\title{
RANCANG BANGUN REPACKING DRUM 200 LITER KOROSI HASIL PENGELOLAAN LIMBAH RADIOAKTIF PADAT
}

\section{DESIGN OF REPACKING DRUM 200 LITER OF CORROSION RESULT OF SOLID RADIOACTIVE WASTE MANAGEMENT}

\author{
Dzulfikri Pangestu ${ }^{1}$, Ajrieh Setyawan ${ }^{2}$, Hendro $^{3}$ \\ ${ }^{1}$ Pusat Tekonologi Limbah Radioaktif, BATAN \\ Email:dzulfikri@batan.go.id \\ ${ }^{2}$ Pusat Teknologi Limbah Radioaktif, BATAN \\ Email:ajrieh@batan.go.id \\ 2 Pusat Teknologi Limbah Radioaktif, BATAN \\ Email: hendros@batan.go.id
}

Diterima: 15 Maret 2021, diperbaiki : 29 Maret 2021, disetujui : 6 April 2021

\begin{abstract}
ABSTRAK
RANCANG BANGUN REPACKING DRUM 200 LITER KOROSI HASIL PENGOLAHAN LIMBAH RADIOAKTIF PADAT TERKOMPAKSI. Telah dilakukan repacking drum 200 liter korosi hasil pengolahan limbah radioaktif padat terkompaksi di Pusat Teknologi Limbah Radioaktif (PTLR). Repacking drum dilakukan terhadap drum 200 liter yang mengalami korosi cukup parah jika dilihat secara bentuk fisik dan diperkuat dengan melakukan pengukuran paparan dari drum 200 liter yang korosi. Tujuan dari repacking adalah menjamin keselamatan radiasi dan penanganan lebih lanjut dari drum 200 liter yang mengalami korosi pada penyimpanan limbah di Interm Storage 2 (IS2) Pusat Teknologi Limbah Radioaktif. Tahapan awal dimulai dengan melakukan pendataan terhadap drum 200 liter yang mengalami korosi serta analisa fisik dimensi dari drum 200 liter menjadi produk repacking dalam bentuk shell beton. Desain gambar menggunakan software google sketch up dengan mengubah 3 buah drum 200 liter korosi menjadi shell beton yang memenuhi standar kualitas IAEA (International Atomic Energy Agency) dengan kuat tekan sebesar $20-50 \mathrm{~N} \cdot \mathrm{mm}^{2}$. Hasil desain gambar diperoleh bahwa repacking untuk 3 buah drum 200 liter korosi diperoleh dimensi dengan tinggi $120 \mathrm{~cm}$ dan diameter $138 \mathrm{~cm}$. Untuk mencapai kuat tekan yang sesuai standar IAEA digunakan matriks semen camp beton K500 lengkap dengan besi bertulang. Hasil akhir kegiatan repacking drum 200 liter korosi diperoleh bahwa untuk satu buah proses menggunakan 3 buah drum 200 liter yang mengalami korosi dan kualitas beton dapat diterima karena sesuai dengan standar IAEA
\end{abstract}

Kata Kunci : Drum 200 liter korosi, limbah radioaktif padat terkompaksi, repacking drum, matriks semen camp beton $\mathrm{K} 500$.

\section{ABSTRACT}

DESIGN OF 200 LITER REPACKING DRUM OF CORROSION RESULT OF COMPACTED SOLID RADIOACTIVE WASTE TREATMENT. Repacking the 200 liter drum of corrosion from the processing of packed solid radioactive waste has been carried out at the Radioactive Waste Technology Center (PTLR). Repacking the drum was carried out on the 200 liter drum which was corroded quite severely when viewed physically and strengthened by measuring the exposure of the corroded 200 liter drum. The purpose of repacking is to ensure radiation safety and further handling of corroded 200 liter drums in the waste storage at Interm Storage 2 (IS2) Radioactive Waste Technology Center. The initial stage was carried out by collecting data on the 200 liter drum which had corrosion and also analyzing the physical dimensions of the 200 liter drum into 
the repacking product in the form of a concrete shell. The image design uses google sketch up software by converting 3200 liter corrosion drums into a concrete shell that meets the IAEA (International Atomic Energy Agency) quality standards with a compressive strength of $20-50$ N.mm2. The results of the design image show that repacking for 3200 liter corrosion drums obtained dimensions with a height of $120 \mathrm{~cm}$ and a diameter of $138 \mathrm{~cm}$. To achieve compressive strength according to IAEA standards, a cement matrix of $\mathrm{K} 500$ concrete camp complete with reinforced steel is used. The final result of the repacking activity of 200 liter of corrosion drum shows that for one process using 3200 liter drums which experience corrosion and the quality of the concrete is acceptable because it is in accordance with IAEA standards.

Keywords: Corrosion 200 liter drum, compacted radioactive waste, drum repacking, K500 concrete camp cement matrix.

\section{PENDAHULUAN}

$\begin{array}{lrr}\text { Pengelolan limbah } & \text { radioaktif } \\ \text { padat di } & \text { Pusat } & \begin{array}{l}\text { Teknologi } \\ \text { Limbah }\end{array} \\ \text { Radioaktif }\end{array}$ dikelompokkan menjadi limbah radioaktif padat terkompaksi, limbah radioaktif padat terbakar, limbah radioaktif tak terbakar tak terkompaksi. Limbah radioaktif padat terkontaminasi ditimbulkan dari kegiatan pemanfaatan teknologi nuklir. Limbah padat yang dapat dikompaksi meliputi kaca atau gelas ukur, HEPA filter, kaleng atau botol. Limbah tersebut ditampung dalam drum 100 liter yang di dalamnya dilapisi plastik agar ketika dilakukan pengepressan tidak terpencar. Drum 100 liter tersebut ditutup rapat dan dikunci agar ketika dilakukan pressing tidak terbuka. Pressing drum 100 liter dilakukan di dalam drum 200 liter menggunakan hidrolik dengan daya tekan sebesar $600 \mathrm{kN}$. Dalam satu drum 200 liter biasanya mampu menampung 4-6 buah drum 100 liter tergantung jenis limbah yang akan dikompaksi. Drum 200 liter yang telah berisi limbah kemudian diisi batu koral ataupun dengan batu kerikil. Pada bagian atas drum diberi sebuah palang dispersal yang berfungsi sebagai pengunci, agar limbah yang ada di dalamnya tidak naik ketika drum 200 liter diisi matriks semen. Setelah itu, drum 200 liter ditempatkan pada meja getar dan diisi semen. Tujuan penempatan pada meja getar agar semen dapat mengisi sampai pada bagian bawah drum 200 liter. Proses tersebut dinamakan imobilisasi sementasi shell drum 200 liter [1]. Imobilisasi termasuk ke dalam kondisioning limbah radioaktif. Kondisioning limbah radioaktif ialah kegiatan pengkondisian limbah radioaktif ke dalam wadah tertentu sehingga radionuklida terkungkung di dalam wadah limbah dan tidak mudah lepas ke lingkungan[2].

Proses akhir dari pengelolaan limbah radioaktif padat terkompaksi ialah melakukan penyimpanan drum 200 liter ke interm storage yang ada di Pusat Teknologi Limbah Radioaktif. Drum 200 liter tersebut disusun di atas palet kayu. Dalam satu palet kayu dapat memuat 4 buah drum 200 liter. Palet kayu yang memuat 4 buah drum 200 liter dimasukkan ke sebuah gudang penyimpanan yang disebut interim storage yang ada di Pusat Teknologi Limbah Radioaktif. Namun saat ini, hasil proses imobililisasi yang telah dilakukan pada tahun-tahun sebelumnya banyak sekali drum yang mengalami korosi. Korosi merupakan penurunan mutu logam yang disebabkan oleh reaksi elektrokimia antara logam dengan lingkungan sekitarnya ${ }^{[3]}$. 
Oleh karena itu diperlukan suatu kegiatan repacking drum 200 liter yang mengalami korosi dengan menggunakan material semen. Material semen dipilih agar korosi yang terjadi pada drum 200 liter tidak terjadi lagi.

Repacking drum dilakukan terhadap drum 200 liter yang mengalami tingkatan korosi cukup parah jika dilihat secara bentuk fisiknya. Dan juga diperkuat dengan melakukan pengukuran paparan radiasi terhadap drum 200 liter korosi tersebut agar bisa memastikan ada atau tidak radionuklida yang bocor dari drum 200 liter yang mengalami korosi.

\section{TEORI}

Pengelolaan limbah radioaktif menurut Peraturan Pemerintah No. 61 Tahun 2013 adalah merupakan rangkaian kegiatan yang meliputi pengumpulan, pengelompokan, pengolahan, pengangkutan, penyimpanan, dan atau pembuangan limbah radioaktif $\left.{ }^{4}\right]$.

Pengolahan limbah radioaktif dengan cara imobilisasi shell drum 200 liter dengan menggunakan matriks semen dilakukan untuk mengungkung dan mengurangi dosis paparan radiasi yang dihasilkan oleh limbah[5]

Repacking drum 200 liter menggunakan bahan dasar matriks semen. Semen yang digunakan ialah semen camp beton K500. Semen camp beton K500 maksudnya ialah semen beton yang hasil nilai kuat tekan benda uji kubus pada umur 28 hari sebesar 500 $\mathrm{kg} / \mathrm{cm}^{2}$. Kuat tekan beton itu sendiri merupakan beban tekan yang dapat dipikul suatu benda uji/ sample dari beton tersebut sampai runtuh. Menurut buku pedoman pekerjaan beton miliki PT.Wijaya Karya, jenis-jenis mutu beton dibagi ke dalam 4 macam, yaitu[7]:
1. K125-<K175: Digunakan sebagai lantai kerja atau

penimbunan kembali dengan beton

2. K175-<K250 : Digunakan sebagai struktur beton tanpa tulangan, misalnya beton siklop, trotoar dan pasangan batu kosong yang diisi adukan dan pasangan batu

3. K250-<K400 : Umumnya digunakan untuk beton bertulang, misalnya pelat lantai jembatan, gelagar beton bertulang, diagfragma, goronggorong beton bertulang, dan bangunan bawah jembatan.

4. K400-K800 : Umumnya digunakan untuk beton prategang, seperti tiang pancang beton prategang, gelagar beton prategang dan sejenisnya.

Beton adalah bahan konstruksi yang berbasis perekat semen, dan agregatnya berupa: pasir dan batu (kerikil) ${ }^{6]}$.

Semen Portland atau biasa disebut semen adalah bahan pengikat hidrolis berupa bubuk halus yang dihasilkan dengan cara menghaluskan klinker (bahan ini terutama terdiri dari silikat-silikat kalsium yang bersifat hidrolis), dengan batu gips sebagai bahan tambahan ${ }^{[8]}$.

Kualitas beton yang digunakan untuk repacking drum 200 liter yang mengalami korosi harus memenuhi standar IAEA (International Atomic Energy Agency) di antaranya yaitu[9]:

- Densitas : 1,70 - 2,50 g.cm-3

- Kuat tekan beton yang telah berumur 28 hari 20,0-50,0N. $\mathrm{mm}^{-2}$

- Laju cairan radionuklida terimobilisasi dalam beton : $1,70 \cdot 10^{-1}-250 \cdot 10^{-4} \mathrm{~g} \cdot \mathrm{cm}^{-2}$. hari-1 .

- Laju dosis pada permukaan kontak < 200 mrem.jam-1. 
- Laju dosis pada jarak $1 \mathrm{~m}$ dari permukaan kontak 10 mrem.jam 1 .

- Laju dosis di luar interm storage $<0,50$ mrem.jam $^{-1}$.

\section{METODE}

Dalam kegiatan rancang bangun repacking drum 200 liter yang mengalami korosi memerlukan suatu bahan dan juga peralatan yang akan digunakan. Bahan tersebut meliputi :

1. Adonan semen camp beton K500

2. Kawat ram, da

3. Drum 200 liter yang korosi.

Selain bahan, diperlukan juga sebuah peralatan sebagai penunjang dalam kegiatan proses repacking drum 200 liter, di antaranya ialah :

1. Crane kapasitas 3,2 ton

2. Forklift kapasitas 6 ton

3. Cetakan repacking drum 200 liter, dan

4. 1 set toolbox.

Proses kegiatan repacking drum 200 liter melalui beberapa tahapan yang meliputi, pendataan drum 200 liter limbah radioaktif yang mengalami korosi, menentukan ukuran cetakan repacking drum yang akan digunakan, membuat desain cetakan repacking drum dengan software google sketchup, dan yang terakhir melakukan kegiatan repacking drum 200 liter limbah radioaktif. Semua tahapan proses tersebut tertuang di dalam flowchart seperti ditunjukkan dalam Gambar 1.

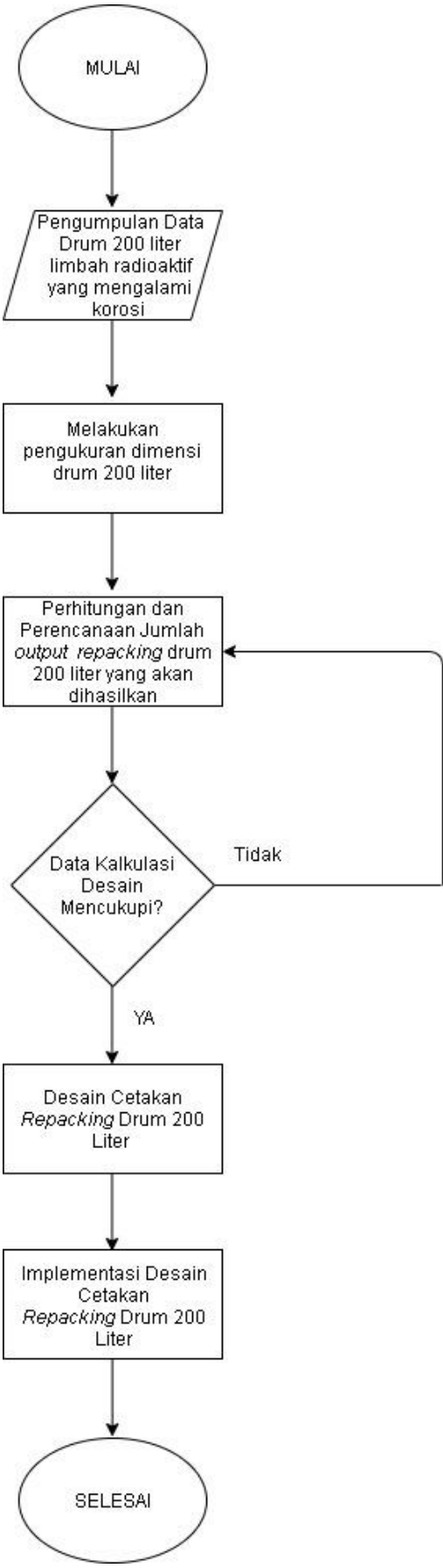

Gambar 1. Flowchart Proses Repacking Drum 200 Liter 
Proses rancang bangun repacking drum 200 liter yang dijelaskan dalam flowchart tersebut, melalui beberapa tahapan sebagai berikut :

1. Pendataan drum 200 liter yang mengalami korosi. Yang dicatat dalam pendataan meliputi identitas dan banyaknya drum yang mengalami korosi. Pengecekan identitas drum yang tidak diolah sangat perlu dilakukan juga agar mudah dalam penelusuran isi dan waktu pengelolaanya.

2. Setelah pendataan terhadap drum 200 liter yang mengalami korosi, selanjutnya dilakukan pengukuran terhadap dimensi drum 200 liter. Pada tahapan ini didapatkan dimensi dari drum 200 liter yang berukuran diameter $60 \mathrm{~cm}$ dan tinggi $80 \mathrm{~cm}$.

3. Setelah pengukuran dimensi, tahap selanjutnya adalah perhitungan dan perencanaan apakah drum 200 liter yang mengalami korosi akan di repacking satu persatu atau digabung menjadi satu dan membentuk sebuah shell beton.

4. Setelah dilakukan perhitungan dan perencanaan terkait desain, dapat disimpulkan bahwa hasil akhir dari rancang bangun repacking drum 200 liter adalah dalam bentuk shell beton yang di dalamnya dapat memuat 3 buah drum 200 liter yang mengalami korosi.

5. Tahap selanjutnya yaitu desain cetakan repacking drum 200 liter. Desain dilakukan dengan menggunakan software google sketchup.

6. Setelah desain cetakan repacking drum 200 liter dihasilkan, langkah terakhir ialah mengimplementasikan desain cetakan repacking drum 200 liter yang telah dibuat.

\section{HASIL DAN PEMBAHASAN}

\section{Pengumpulan data drum 200 liter yang korosi dan pengkuran dimensi drum 200 liter}

Telah didapatkan data, bahwa jumlah drum 200 liter hasil olah pengelolan limbah radioaktif padat terkompaksi yang mengalami korosi sebanyak 6 buah. Data tersebut akan ditampilkan pada tabel di bawah ini.

Tabel 1. Data Drum 200 Liter Yang Korosi

\begin{tabular}{|c|c|c|c|}
\hline $\begin{array}{c}\text { No. } \\
\text { Drum } \\
200 \mathrm{~L}\end{array}$ & \multicolumn{2}{|c|}{$\begin{array}{c}\text { Paparan } \\
\text { Setelah Diolah } \\
\text { (mR/jam) }\end{array}$} & $\begin{array}{c}\text { Tanggal } \\
\text { Pengolahan }\end{array}$ \\
\cline { 2 - 4 } & Kontak & $1 \mathrm{M}$ & \\
\hline 20 & 2,8 & 0,9 & $11-10-1991$ \\
\hline 23 & 1,8 & 0,8 & $28-10-1991$ \\
\hline 565 & 2,01 & 0,60 & $27-10-2004$ \\
\hline 605 & 0,052 & 0,032 & $20-09-2005$ \\
\hline 164 & 0,03 & 0,02 & $02-01-2000$ \\
\hline 572 & 0,37 & 0,25 & $29-10-2004$ \\
\hline
\end{tabular}

Ukuran drum 200 liter memiliki tinggi 80 $\mathrm{cm}$ dan diameter $60 \mathrm{~cm}$.

\section{Proses desain cetakan repacking drum 200 liter}

Pada proses desain ini, direncanakan dalam satu repacking akan terdapat 3 buah drum 200 liter. Satu repacking tersebut akan ditempatkan di atas sebuah palet besi yang telah dirancang sedemikian rupa agar bisa menampung 3 buah drum 200 liter di atasnya. Di atas palet besi akan dipasangkan sebuah plat besi berbentuk lingkaran dengan diameter $138 \mathrm{~cm}$ yang akan digunakan sebagai dasar dari repacking drum 200 liter. 


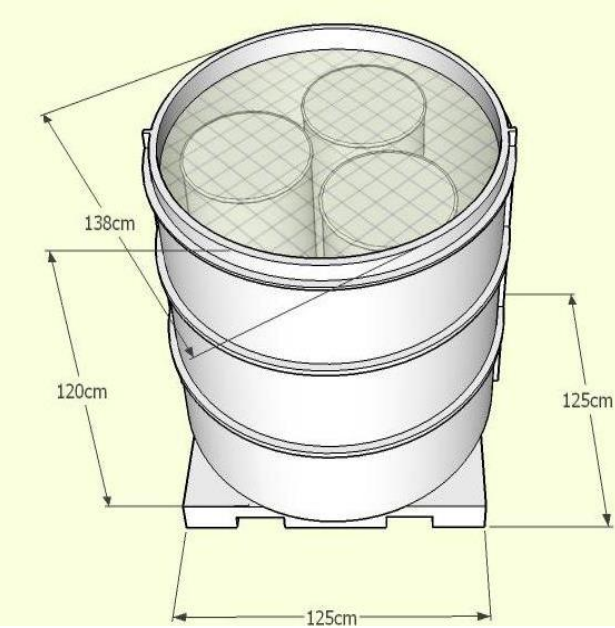

Gambar 2. Desain Cetakan Repacking Drum 200 Liter

Hasil repacking tersebut akan ditempatkan di sebuah palet besi dengan ukuran $125 \mathrm{~cm} \times 125 \mathrm{~cm}$. Pada proses realisasi nanti, akan dibuat sebuah kerangka besi dengan bentuk seperti cetakan repacking. Kerangka besi ini digunakan sebagai pondasi yang diharapkan mampu menahan atau menopang gaya tekan pada saat beton mengering. Setelah kerangka dibuat, selanjutnya semen camp beton K500 akan dimasukkan ke dalam cetakan yang telah dipasang. Setelah semen camp beton $\mathrm{K} 500$ mengeras, maka cetakan repacking bisa dilepas kembali dan dapat digunakan untuk me-repacking drum 200 liter yang lainnya.

Setelah cetakan diisi dengan adonan semen dan cetakan repacking telah dilepas, maka hasil akhir dari repacking drum 200 liter diharapkan akan terlihat seperti Gambar 3.

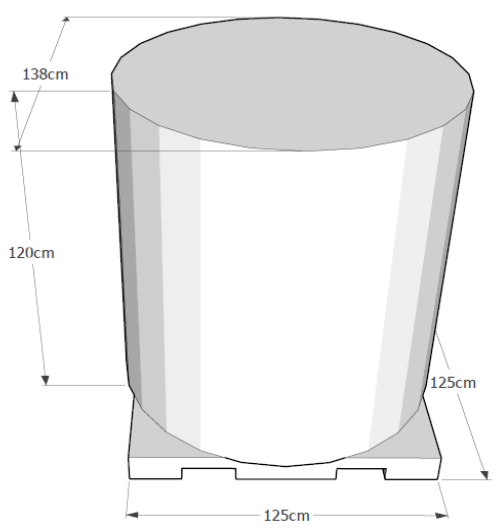

Gambar 3. Hasil Akhir Repacking Drum 200 Liter 


\section{Pembuatan kerangka}

Kegiatan ini dilakukan oleh pihak ketiga. Pada tahap ini dibuat sebuah kerangka yang telah diukur sedemikian rupa agar menyerupai bentuk rancangan yang telah dibuat terlebih dahulu.
Kerangka ini nantinya akan dijadikan sebagai pondasi yang diharapkan mampu menahan gaya tekan dari beton tersebut.- Proses pembuatan kerangka dapat dilihat pada Gambar 4.

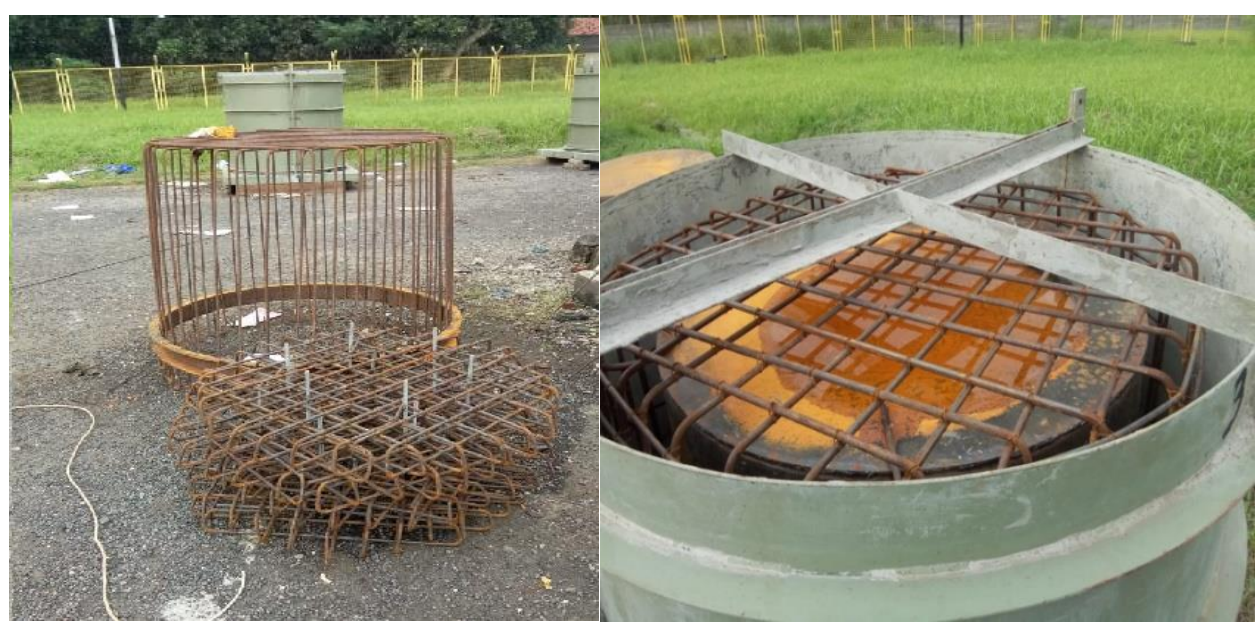

Gambar 4. Membuat Kerangka Repacking Drum 200 Liter

Setelah pembuatan kerangka, langkah selanjutnya yaitu modifikasi palet besi yang akan digunakan untuk penempatan. Modifikasi di sini maksudnya ialah menambahkan penampang berbentuk lingkaran dengan diameter sebesar $138 \mathrm{~cm}$. Penampang ini nantinya akan digunakan sebagai bagian dasar untuk penampatan 3 buah drum 200 liter. Gambar palet besi yang telah dimodifikasi dapat dilihat pada Gambar 5.

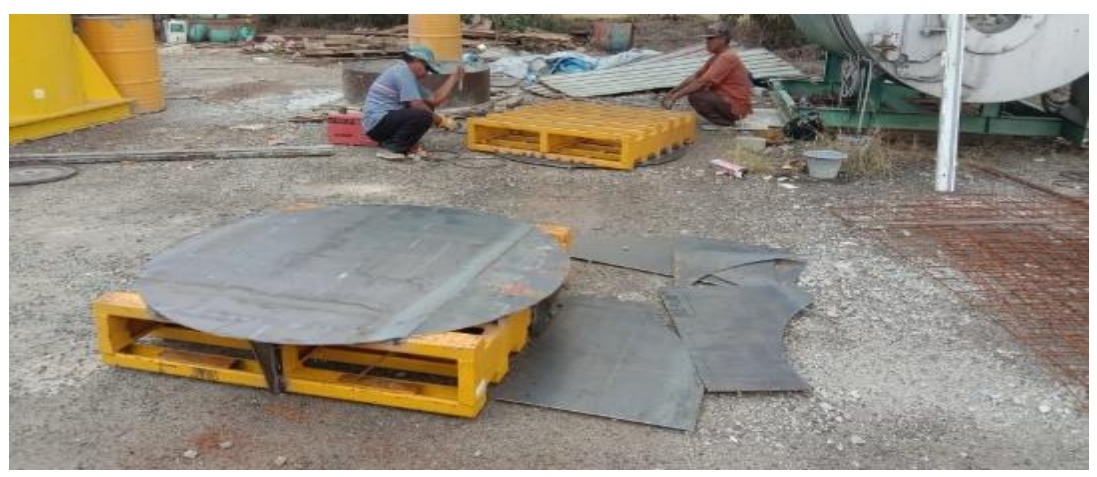

Gambar 5. Palet Besi Yang Telah Dimodifikasi. 
Selanjutnya, setelah pembuatan kerangka dan modifikasi palet besi, kedua bagian tersebut disusun menjadi satu terlebih dahulu agar mudah dalam penyusunan 3 buah drum 200 liter dengan alat bantu sebuah crane 3,2 Ton. Proses penyusunannya dapat dilihat pada Gambar 6.

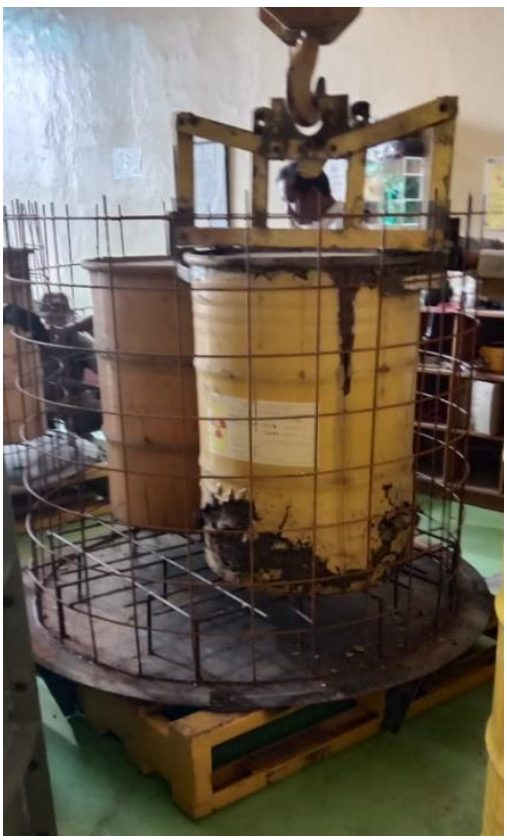

Gambar 6. Proses Penyusunan Drum 200 Liter.

Setelah 3 buah drum 200 liter dimasukkan ke dalam kerangka repacking, langkah selanjutnya ialah mulai pemasangan cetakan repacking. Ukuran dari cetakan repacking ini sesuai dengan rancangan design yang telah dibuat sebelumnya yaitu dengan tinggi $120 \mathrm{~cm}$ dan dengan diameter $138 \mathrm{~cm}$. Ukuran tersebut ditentukan dengan mempertimbangkan ukuran dari drum 200 liter itu sendiri. Ukuran drum 200 liter yaitu diameter sebesar $60 \mathrm{~cm}$ dengan tinggi $80 \mathrm{~cm}$. Gambar 7 menunjukkan ketika repacking drum 200 liter siap untuk penuangan adonan semen camp beton K500.

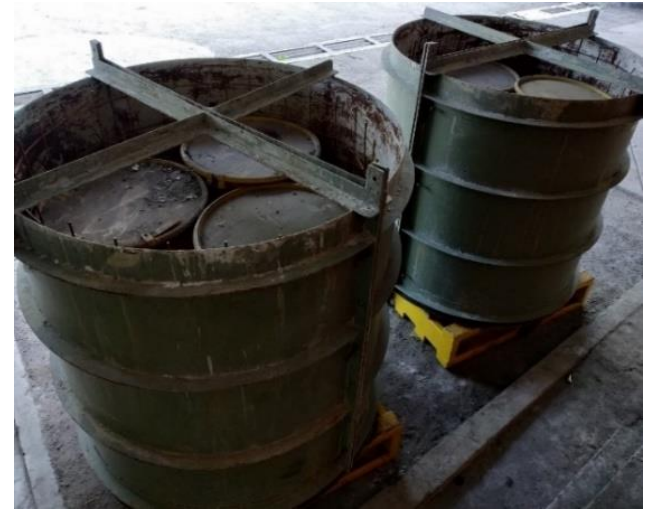

Gambar 7. Pemasangan Cetakan Repacking Yang sudah Diisi 3 buah Drum 200 liter

\section{KESIMPULAN}

Repacking drum 200 liter merupakan salah satu upaya untuk mengatasi korosi pada drum 200 liter hasil olah limbah radioaktif padat terkompaksi yang dilakukan oleh Subbidang Pengelolaan Limbah Radioaktif yang ada di Pusat Teknologi Limbah Radioaktif (PTLR). Pada kegiatan ini, sebanyak 6 buah drum 200 liter hasil olah limbah radioaktif padat terkompaksi yang telah dilakukan repacking. Enam (6) drum tersebut dikelompokkan menjadi 2 buah kelompok. Satu kelompok diisi dengan 3 buah drum 200 liter lalu di repacking ulang dengan menggunakan bahan dasar semen camp beton K500.

Oleh karena itu, diharapkan nanti pada saat besaran paparan yang ada pada drum 200 liter hasil olah limbah radioaktif padat terkompaksi telah mencapai tingkat klieren, maka hasil repacking drum 200 liter bisa digunakan sebagai pondasi untuk membangun jembatan.

Dan kegiatan repacking drum 200 liter ini akan terus berlangsung secara bertahap untuk mengatasi drum 
200 liter hasil olah limbah radioaktif pada terkompaksi yang mengalami korosi.

\section{UCAPAN TERIMAKASIH}

Penulis mengucapkan terima kasih kepada Koordinator Bidang Pengelolaan Limbah Radioaktif dan seluruh staff yang terlibat dalam kegiatan rancang bangun repacking drum 200 liter korosi hasil pengelolaan limbah radioaktif padat, sehingga karya tulis ini bisa tersusunnya.

\section{DAFTAR PUSTAKA}

[1]. M. Nurhasim dan Ayi Muziyawati, "Pengelolaan Limbah Radioaktif Padat dengan Metode Kompaksi dan Imobilisasi", Prosiding Hasil Penelitian dan Kegiatan, PTLR BATAN, Serpong, 2018. ISSN :0852-2979.

[2]. Ajrieh Setyawan dan Sugeng Purnomo, "Karakterisasi Kualitas Blok Beton untuk Sementasi Resin Bekas", Prosiding Hasil Penelian dan Kegiatan, PTLR BATAN, Serpong, 2018. ISSN:0852-2979.

[3]. Kuat Heriyanto, "Kualitas Preparasi Sampel Analisis Korosi Menggunakan Potentiostate, Prosiding Hasil Penelitan dan Kegiatan, PTLR BATAN, Serpong, 2018. ISSN: 0852-2979.
[4]. Peraturan Pemerintah No.61 Tahun 2013 tentang Pengolahan Limbah Radioaktif.

[5]. Wasito, "Pengolahan Limbah Radioaktif Padat" , Diktat Diklat Pengelolaan Limbah Radioaktif PTPLR. PTLR BATAN, Serpong, 2018.

[6]. Herdiansyah dan Mekar Ria $P$, "Pengaruh Batu Cadas (Batu Trass) sebagai Bahan Pembentuk Beton terhadap Kuat Tekan Beton", Jurnal Inersia Vol.5 No.2 Oktober 2013, Universitas Ratu Samban, Bengkulu, 2013

[7]. Biro Enjinering PT. WIKA, Pedoman Pekerjaan Beton, PT. WIKA, Jakarta, 2005.

[8]. Aris Sutrisno dan Slamet Widodo, "Analisis Varian Kandungan Semen terhadap Kuat Tekan Beton Ringan Struktural Agregat Pumice", Jurnal Teknik Sipil Universitas Negeri Yogyakarta, Yogyakarta, 2013.

[9]. Mas'udi, Bambang Sugito dan Yayat Bernadi, "Pengolahan Limbah Radioaktif Resin Bekas dengan Metode Sementasi", Prosiding Hasil Penelitian dan Kegiatan, PTLR BATAN, Serpong, 2018. ISSN:08522979. 